\title{
Peripheral orbital nerve schwannoma: Case report
}

\author{
Beatriz J Pérez-Aragón ${ }^{1}$, I González-Olhovich ${ }^{2}$, Julio Cortés ${ }^{3}$, Daniel R Capiz-Correa* ${ }^{4 *}$, and Abelardo A Rodríguez-Reyes ${ }^{5}$ \\ ${ }^{1}$ Uveitis Fellow "Fundación Hospital Nuestra Señora de la Luz IAP”, Mexico \\ ${ }^{2}$ Neuro-ophthalmology of department at National Institute of Neurology and Neurosurgery "Manuel Velasco Suarez", Mexico \\ ${ }^{3}$ Orbit and Oculoplastcis department at "Centro Medico Nacional Hospital 20 de Noviembre”, Mexico \\ ${ }^{4}$ Orbit and Oculoplastics department at "Fundación Hospital Nuestra Señora de la Luz IAP”, Mexico \\ ${ }^{5}$ Pathology department at APEC, Hospital “Dr. Luis Sánchez Bulnes”, Mexico
}

\begin{abstract}
We present a rare case of a peripheral orbital nerve schwannoma. This patient was a 37-year-old man with a lesion that appeared 10 years ago and has gradually enlarged. Examination showed a space-occupying lesion in the right orbit that was firm to palpation, adherent to deep planes, painless and displaced the right eye inferiorly. Computed tomography showed a homogeneous orbital mass that was isodense to the brain parenchyma, encapsulated and did not invade adjacent structures. Complete tumour resection is performed, and pathologic examination showed a schwannoma. Overall orbital Schwannomas are infrequent tumours arising from the orbit coming behind Inflammatory, vascular and lymphoproliferative diseases, treatment is complete resection of the lesion with subsequent monitoring to prevent recurrence.
\end{abstract}

Orbital Schwannoma arising from the trochlear nerve in the anterior orbit with ocular movement recovery after surgery.

\section{Case report}

The first description of a schwannoma was made by Smith in 1861 . Previously known as Neurilemmoma is a benign tumor originating from the nerve sheath composed of schwann cells which normally produce myelin sheath covering the nerves [1-4]. Orbital schwannomas are slow growing, with less than $1 \%$ undergoing malignant transformation to neurofibrosarcoma. The clinical course depends on the localization of the tumor and compression of adjacent structures. They are unilateral and solitary tumors with well demarcated margins. Primary symptoms are: retroocular oppressive sensation, proptosis and in some rare cases pain [1,3-6].

Imaging is important to determine the type of lesion, its localization and adjacent structure compression. With all this the best approach could be determined. Surgical excision is the primary treatment, but radiosurgery and radiotherapy are also alternatives.

A 37-year-old man without any chronic degenerative disease and a history of blunt orbital trauma 10 years previously was evaluated for diffuse right orbital swelling. Examination showed that his visual acuity was 20/40 in his right eye and 20/25 in his left eye. Exophthalmometry showed: OD $20 \mathrm{~mm}$, OS $17 \mathrm{~mm}$; Goldman visual field testing was normal without any alterations; ocular eye movements showed inferior displacement of the right eye, limitation to the superior eye movement on the right eye, inner movement of the right eye limited -1 , and the remainder of his eye movements was complete without restrictions. The remainder of his examination was normal excepted he had a mildly elevated, mildly hyperemic right optic nerve head in his right eye.

A CT scan was obtained of both orbits (Figure1) showed a right orbital mass. The differential diagnoses included a cavernous haemangioma and an orbitotomy was performed. At the time of surgery, a well demarcated orbital mass was resected, which was irregular, elongated, white to yellow colour, and had a mildly firm consistency. The mass seemed to originate from the trochlea and seemed to infiltrate the tendon of the superior oblique. The resected mass measured $60 \times 24 \times 10 \mathrm{~mm}$ (Figure 2).

Pathologic examination showed the mass to be composed of fascicles of fusiform to oval cells, some of them forming a palisading pattern and Verocay bodies. Hypercellular zones (Antoni A pattern) alternating with hypocellular zones (Antoni B pattern) The diagnosis was schwannoma (Figure 3).

At 3 years follow- up, the patient's vision was 20/25 in his right eye, optic nerve head swelling eye movements restrictions and lower
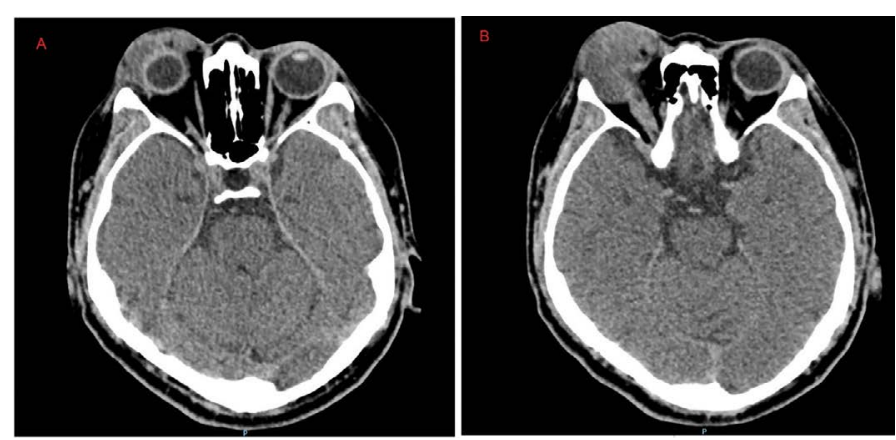

Figure 1. A) Computed tomography axial cut showing well demarcated, homogeneous tumor, isodense to the brain without invasion of the eye. B) computed tomography axial cut showing inferior displacement of the right eye, intraconal invasion, no evidence of bone alterations or invasion of adjacent structures.

${ }^{*}$ Correspondence to: Daniel R. Capiz-Correa, Orbit and oculoplastics department "Fundación Hospital Nuestra Señora de la Luz IAP". Calle Ezequiel Montes 135, Tabacalera, 06030 Cuauhtémoc, CDMX, México; Tel: +52 555128 1140 ext 207; E-mail: dr.capiz@hotmail.com

Received: April 11, 2018; Accepted: April 23, 2018; Published: April 26, 2018 


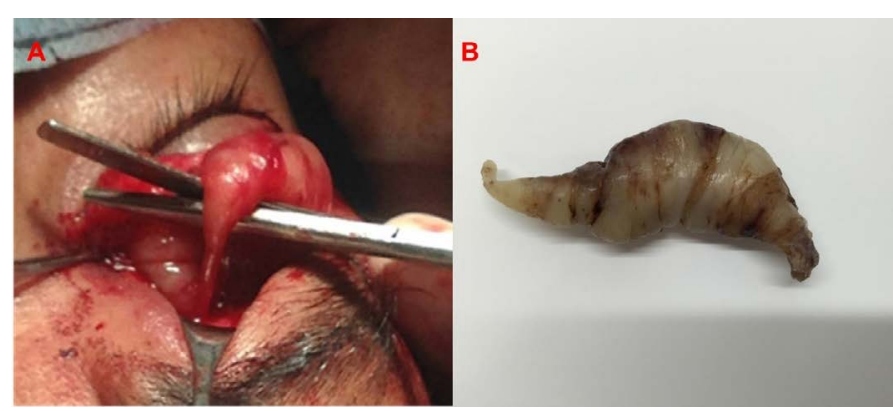

Figure 2. A) Anterior, white to yellow, encapsulated orbital tumor showing trochlear involvement. B) Gross Photograph of completely resected tumor.
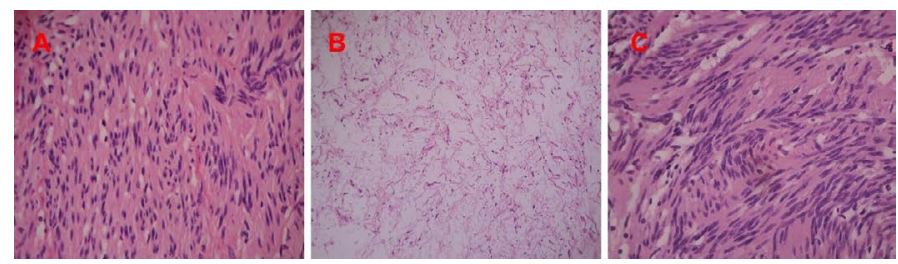

Figure 3. A) Antoni A pattern showing hipercelular areas. B) Antoni B pattern showing hipocelular areas. C) Verocay bodies, palisading pattern alternating with cytoplasmatic process. (hematoxylin and eosin, 20X).

displacement of the right eye resolved, no evidence of recurrence has been documented.

\section{Discussion}

Neurogenic tumors arising from the orbits are rare. Orbital schwannomas present between 20 and 70 years of age (median of 40 years). They are benign asymptomatic tumors that can manifest with proptosis and diplopia, other manifestations during neuroophthalmologic examination are optic nerve edema, optic nerve redness, optic atrophy and pupillary reflex alterations 1, 3-5. Sometimes they can produce cosmetic alterations depending of its size and location. Our patient presented with a tumor larger than the reported by 2015 by Jia Li et al. of $32 \times 18 \times 8$ compared to our case of $60 \times 24 \times 10 \mathrm{~mm}$ causing asymmetry and proptosis [7]. In the orbit, schwannomas are usually unilateral and can develop from the supraorbitary, infraorbitary, supratrochlear, ciliary, oculomotor, trochlear or abducens nerve [1,3-7].

The diagnosis is confirmed by histopathologic exam; macroscopically they may present as fusiform mass adjacent to the affected nerve. Microscopically two parts can be distinguished zones types Antoni A, forming a dense structure, highly cellular, palisading nuclei formation (Verocay bodies); Antoni type B, loose and edematous structure, lower cellularity and myxoid stroma [1,8-10]. The myxoid component correlates to the Magnetic resonance imaging showing a well-defined, similar intensity as the gray matter in T1 imaging, and hyperintense images in $\mathrm{T} 2$. When there are cavitations within the tumor structure the imaging in heterogenous in $\mathrm{T} 2$ and relates to Antoni B pattern. When $\mathrm{T} 2$ images are more intense and homogeneous (less water content) it correlates to Antoni A pattern [1,2,4,5,9-12].
It is important to differentiate schwannomas from other orbitary tumors such as hemangiomas, solitary fibrous tumors, and their primary differential diagnosis should be made with peripheral nerve sheath tumors such as neurofibromas, which differ mainly in its microscopic features $[1,6,11]$. The use of immunohistochemistry markers is of low utility because both tumors express S-100 protein, and meningiomas should also be differed by their microscopic features because of their similar localizations as schwannomas [1].

Excisional biopsy is the treatment of choice and it should be completely removed as soon as it is diagnosed, to prevent optic nerve compression. The nerve of origin is not identified in up to $50 \%$ of cases 2, in our patient's case the surgical removal was difficult because of the superior oblique tendon affection. Highly cellular tumors have a higher recurrence rate and malignant transformation, thus early removal is recommended $[1,2-4,7]$. Follow up of our patient at 3 years showed that he is asymptomatic and does not have any recurrence. We recommend a complete check-up because of the possible systemic associations, such as neuro-cutaneous syndromes associated with multiple neurofibromas, schwannomas, meningiomas and gliomas of intracranial origin and spinal nerve affection; nevertheless, spinal nerve compression is more common due to extra medullar tumor growth $[2,11]$.

\section{References}

1. Rootman J, Goldberg C, Robertson W (1982) Primary orbital schwannomas. Br J Ophthalmol 66: 194-204. [Crossref]

2. Evans DG, Baser ME, McGaughran J, Sharif S, Howard E, et al (2002) Malignan peripheral nerve sheath tumours in neurofibromatosis 1. J Med Genet 39: 311-314. [Crossref]

3. Rato RM, Correia M, Cunha JP, Roque PS (2012) Intraorbital abducens nerve schwannoma. World Neurosurg 78: 375.e1-4. [Crossref]

4. Samadian M, Farzin N, Bakhtevari MH, Hallajnejad M, Rezaei O (2015) Isolated trochlear nerve schwannoma presenting with diplopia: A case report and literature review. Interdiscip Neurosurg 2: 111-114

5. Abe T, Kawamura N, Homma H, Sasaki K, Izumiyama H, et al. (2000) MRI of orbital schwannomas. Neuroradiology. 42: 466-468.

6. Santaolalla F, Sanchez JM, Ereño C, Lecumberri G, Valdes C (2009) Severe exophthalmos in trigeminal plexiform neurofibroma involving the orbit and the infratemporal fossa. J Clin Neurosci 16: 970-972. [Crossref]

7. Li J, Lin J, Liu R, Li J, Yan J (2015) Orbital schwannoma originating from the superior oblique muscle. J Craniofac Surg 26: 559-60. [Crossref]

8. Gündüz K, Shields CL, Günalp I, Erden E, Shields JA (2003) Orbital schwannoma: correlation of magnetic resonance imaging and pathologic findings. Graefes Arch Clin Exp Ophthalmol 241: 593-597. [Crossref]

9. Pilavaki M, Chourmouzi D, Kiziridou A, Skordalaki A, Zarampoukas T, et al. (2004) Imaging of peripheral nerve sheath tumors with pathologic correlation: pictorial review. Eur J Radiol 52: 229-239. [Crossref]

10. Pérez-Rivera O, Sarmiento M, Ortiz-Rivera T, et al. Neurilemoma del muslo de tipo Antoni A. Revista Cubana de Ortopedia y Traumatología. [serial online]. 2010 nov; 24(1). Available at: http://scielo.sld.cu/scielo.php?script=sci_arttext\&pid=S0864215X2010000100009\&lng=es\&tlng=es. Accessed March 2, 2013.

11. Atanasio-Moreno E, Capellas-Sanz L, Tinoco-Gonzalez J, Martinez-Escudero C (2005) Neurofibromatosis y schwannoma. A propósito de un caso. Revisión de la literatura. Rehabilitación. 39: 81-84.

12. Muñoz S (2003) Tumores nuerogénicos de nervios periféricos: estudio por imagen. Rev chil. Radiol 9: 124-136.

Copyright: (C2018 Pérez-Aragón BJ. This is an open-access article distributed under the terms of the Creative Commons Attribution License, which permits unrestricted use, distribution, and reproduction in any medium, provided the original author and source are credited. 